\title{
Optimal Sizing of Mobile Hybrid Off-Grid Multi-Sources Installation
}

Majdi Saidi, Seifeddine Ben Elghali, Zhongliang Li, Rachid Outbib, Thiery Le Roux and Emmanuel Cardone

\begin{abstract}
In many situations, the access to energy can be compromised or limited as for refugee crisis zones, rural areas and military camps. Therefore, it is crucial to be able to ensure the basic electric needs with an off-grid power solution. In this paper, an optimal sizing of a mobile renewable hybrid power system is presented. The proposed solution is composed of a container equipped with a diesel generator, batteries and a photovoltaic system. The optimization process takes into account the particularity of the consumer needs and the accessibility to the local renewable energy resources. In order to investigate the solution performances, simulation results under Matlab $\backslash$ Simulink ${ }^{\circledR}$ are presented and analyzed.
\end{abstract}

Index Terms-Optimal sizing, multi-sources, off-grid, batteries, photovoltaic, diesel generator.

\section{NOMENCLATURE}

\begin{tabular}{ll}
\multicolumn{2}{l}{ Superscript and subscript } \\
$b a t$ & Battery \\
$c h$ & Charge \\
$d c h$ & Discharge \\
$D G$ & Diesel generator \\
max & Maximum \\
min & Minimum \\
$p v$ & Photovoltaics \\
Variable \\
$\Delta t$ & Sampling period \\
$A$ & Surface \\
$C$ & Price per unit \\
$E$ & Energy \\
$E D$ & Energy deficit \\
$G$ & Solar radiation \\
$N$ & Number \\
$P$ & Power \\
$S O C$ & State of charge \\
$T$ & Time length \\
$t$ & Time instant \\
$\mathcal{T}$ & Concerned period
\end{tabular}

M. Saidi is with the LIS Lab (UMR CNRS 7020), Aix-Marseille University, 13397 Marseille Cedex 20, France and LITTLE HORSE Fire Division of Pompes Chaud Froid Industrie, 13420 Gemenos, France (e-mail: majdi.saidi@lislab.fr)

S. Ben Elghali, Z. Li, R. Outbib are with the LIS Lab (UMR CNRS 7020), Aix-Marseille University, 13397 Marseille Cedex 20 (e-mail: seifeddine.benelghali@lis-lab.fr; zhongliang.li@lis-lab.fr; rachid.outbib@lislab.fr)

T. leroux and E. Cardonne are with Energy Mechanical Building company, 13420 Gemenos, France. (e-mail: t.leroux@little-horse.com,be.info@littlehorse.com)

\section{INTRODUCTION}

Nowadays, power generation and power consumption are becoming more and more diversified. Accordingly, the power supply systems are designed more and more smartly to match the power generation and consumption characteristics. Among different power users and unlike the permanent power users, temporary power supply is widely required in a large number of cases, such as construction, outdoor social events, utilities, remote and telecommunications [1], [2]. In practice, as power supply is temporary, the power supply systems are usually required to be mobile rather than fixed, and to be modular and easily scalable [3].

Depending on the specific power level and application, different power sources can be considered for a mobile power system. In most commercial products, such as those used as uninterrupted power supplier, diesel generators are the most used power sources. However, drawbacks of diesel based mobile power supply, such as high pollution and high fuel cost, have evoked extensive consideration of the local available renewable energy as alternative source to reduce or completely replace the use of diesel generator (DG) [4], [5]. In some critical applications, outdoor military and medical centers for instance, the high noise and the high pollution from a DG are even intolerable. In order to overcome the drawbacks of DG, new strategies have to be explored for reducing its use and for improving its functioning. The reduction of DG use can be achieved generating the demanded energy from hybrid systems using renewable resources and energy storage units [6]. The improvement of the DG functioning can be realized by a suitable control and energy management strategy in system level (see [7] and the references therein). Actually, as the growing interests and the technological advances in renewable technologies, it could be predicted that more and more renewable energy will be considered in the mobile power system designs. In the cases where the use of renewable energy is possible and desirable, battery storage is usually accompanied to exploit the renewable energy more sufficiently and to further reduce or eliminate the use of DG.

Some mobile temporary power supply systems, consisting of renewable power sources, have been proposed. These proposals are mainly published in some patents (see for instance [8] [9]). However, most of these designs are limited on the conception level, whereas a quantitative analysis and design for this special type of power system has not yet been pro- 
posed. Proper sizing of a such mobile energy system is the key element in the system design. A properly sized energy system can potentially provide more reliable, less costly power with less environmental pollution and even less system investment [10]. In the literature, many studies have been proposed for sizing both grid-connected and standalone hybrid renewable systems [10]-[12]. As in most cases, a sizing problem can be described as a constrained optimization problem. Once the optimization problem is formulated for a specific case, a variety of optimization methods have also been studied and proposed for this application. Although these studies provide abundant references, the sizing of the mobile power system containing renewable sources has not yet been sufficiently investigated. Actually, some special considerations should be taken into account in the design process of a mobile temporary system. For instance, the system should be able to satisfy various uses, which have different requirements. The system should be able to be installed in different installing conditions, e.g., surface limit, weight limit, climatic condition.

The main objective of the work is to propose the optimal sizing of a mobile power supplier dedicated to a particular use. The considered system consists of photovoltaic (PV) panels, DG and batteries. The optimal sizing is realized by adopting the genetic algorithm, and in consideration of the energy management which is achieved based on a rule-based strategy.

The rest of paper is organized as follows: In Section II, the mobile renewable hybrid system is modeled, and the technological limits of different components are presented. Section III provides the energy management algorithm. In Section IV, the sizing optimization problem is firstly formulated and the solving method is detailed. Then, the optimal results are presented and discussed in Section V. The paper is finally concluded in Section VI.

\section{SYSTEM MODELING AND DESIGN CRITERIA}

In this paper, the studied structure is shown in Fig. 1. The system consists of PV system, battery, and DG. According to the particular requirements of users and local renewable resources, different power sources, such as PV system and $\backslash$ or wind turbine and $\backslash$ or hydro-turbine system can be added to the proposed structure.

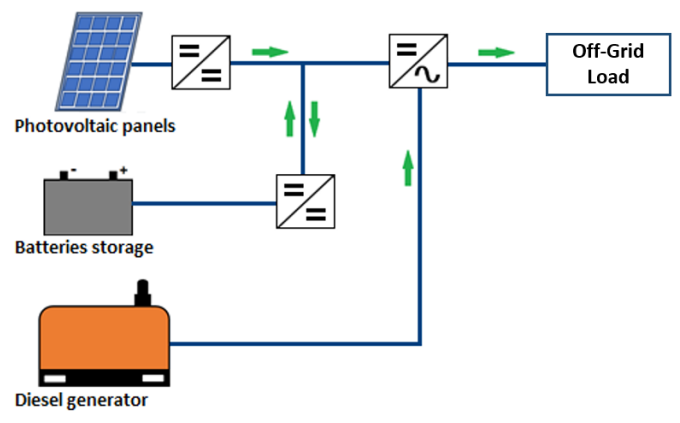

Fig. 1. Mobile Renewable Hybride Power System
In the sequel, the analysis period will be denoted by $\mathcal{T}=(0, T)$ where $T$ is the duration. We define the number of samples by $N_{\mathcal{T}}=\left\lfloor\frac{T}{\Delta t}\right\rfloor$ where $\Delta t$ denotes the sampling period.

\section{A. Photovoltaic system}

Assuming that PV panels used in the considered system are controlled by a maximum power point track regulator, the power generated by a single panel, denoted $P_{P V}(t)$ for $t \in \mathcal{T}$, is expressed as a function of solar radiation [13], by

$$
P_{P V}(t)=G(t) A_{P V} \eta_{P V}, t \in \mathcal{T}
$$

where $G$ represents the solar radiation, $A_{P V}$ is the surface of the PV panel, $\eta_{P V}$ is the efficiency of the PV system.

\section{B. Battery storage system}

The technological constraints of the batteries impose some limitation in charging and discharging power $P_{c h}$ and $P_{d c h}$, respectively. To take into consideration those limits, the variables $T_{c h}$ and $T_{d c h}$ are introduced to define the minimum period of charging and discharging, respectively, and we assume that:

$$
\left\{\begin{array}{l}
T_{d c h} \leq \frac{E_{b a t}(t)}{P_{b a t}(t)} \\
T_{c h} \leq \frac{E_{b a t}(t)}{-P_{b a t}(t)}
\end{array}\right.
$$

where $E_{b a t}$ denotes the energy stored in battery. It is assumed that $P_{c h}(t)<0$, for $t \in \mathcal{T}$, in the considered case since the power flows inversely. The state of charge $S O C$ is the percentage of rest energy in the battery with respect to the full charged energy.

$$
S O C(t)=\frac{E_{b a t}(t)}{E_{b a t}^{\text {max }}}
$$

Based on (2) and (3), it is deduced that

$$
\left\{P_{b a t}(t) \in\left(-\frac{S O C(t) E_{b a t}^{\max }}{T_{c h}}, \frac{S O C(t) E_{b a t}^{\max }}{T_{d c h}}\right) \text { for } t \in \mathcal{T}\right.
$$

Moreover, we have to consider the state of charge limitation where a minimum and maximum values, i.e. $S O C^{\text {min }}$ and $S O C^{\max }$, must be set to preserve the battery from deep discharge and over charging.

$$
S O C(t) \in\left(S O C^{\text {min }}, S O C^{\text {max }}\right) \quad \text { for all } t \in \mathcal{T}
$$

The feasible operating zone of battery is therefore shown in Fig. 2.

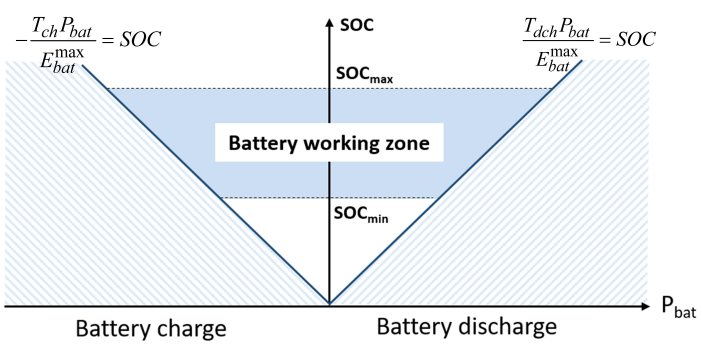

Fig. 2. Battery characteristics 
Thus, the instantaneous limits can be expressed by:

$$
\left\{\begin{array}{l}
P_{b a t}^{\min }(t)=E_{b a t}^{\max } \max \left(\frac{\left(S O C(t)-S O C^{\max }\right)}{\Delta t},-\frac{S O C(t)}{T_{c h}}\right) \\
P_{b a t}^{\max }(t)=E_{b a t}^{\max } \min \left(\frac{\left(S O C(t)-S O C^{\min }\right)}{\Delta t}, \frac{S O C(t)}{T_{d c h}}\right) \\
t \in \mathcal{T}
\end{array}\right.
$$

\section{DG system}

The DG characteristics are described by Fig. 3, where the DG efficiency is given according to the power production. The detailed description of the model can be found in [14]. In this study, the curve shown in Fig. 3 is obtained using a lookup table. It can be noticed that the zone (I) is characterized by a high decreasing slope and the highest efficiencies are obtained near to the rated output power. Therefore, it is highly recommended to work in zone(II) where the diesel efficiency is more than $80 \%$.

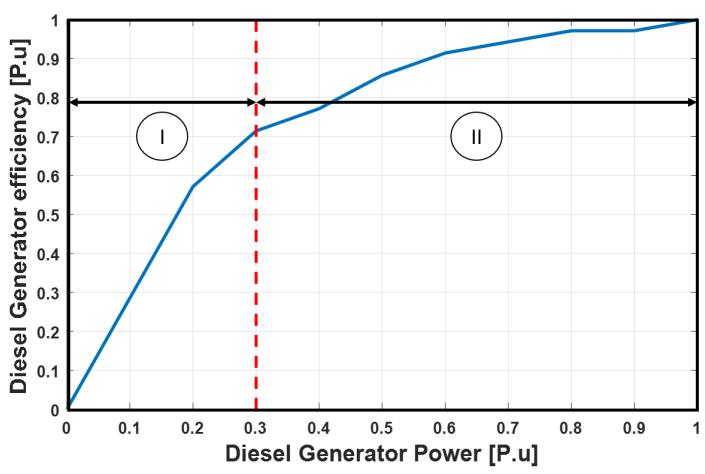

Fig. 3. DG characteristics

\section{ENERGY MANAGEMENT}

Energy management must be considered in the process of calculating the sizing criteria. rule-based energy management strategy is adopted for the concerned system. Depending on the different power values and the battery SOC, the load power can be dispatched differently in multiple cases. The energy management strategy is shown as a flowchart in Fig. 4. One objective of the strategy is to use the PV energy as much possible. Meanwhile, it is also designed to make DG work in the high efficiency or high power zone as possible.

\section{Sizing Optimization}

\section{A. Problem Formulation}

The goal of the sizing optimization is to guarantee the load needs during a period $\mathcal{T}$, ensure the best working conditions for the DG and minimize the investment cost of the whole installation. In this work, we consider that the solar irradiation $G(t)$ and the power load $P_{\text {load }}$ are known during the period $\mathcal{T}$.

In the sequel, the sizing variables considered are the output rated power of the $\mathrm{DG} P_{D G}^{r} \in \mathcal{P}=\left(P_{D G}^{\min }, P_{D G}^{\max }\right)$, the number of battery cells $N_{\text {bat }} \in \mathcal{N}=\left\{0, \ldots, N_{\text {bat }}^{\max }\right\}$ and the
PV panel total surface $S_{p v} \in \mathcal{S}=\left(0, S_{p v}^{\max }\right)$.

In this study, the sizing optimization aims to solve simultaneously three sub-problems under the following constraint

$$
\boldsymbol{\theta} \in \boldsymbol{\Theta}
$$

with $\boldsymbol{\theta}=\left(P_{D G}^{r}, N_{b a t}, S_{p v}\right)^{T}$ and where $\boldsymbol{\Theta}=\mathcal{P} \times \mathcal{N} \times \mathcal{S}$.

More precisely, the objective of the first sub-problem is to minimize the system investment cost, as

$$
\begin{aligned}
\min F_{1}(\boldsymbol{\theta}) & =\langle\boldsymbol{\theta}, \boldsymbol{C}\rangle \\
\text { s.t. } \quad \boldsymbol{\theta} & \in \boldsymbol{\Theta}
\end{aligned}
$$

where $\boldsymbol{C}=\left(C_{D G}, C_{b a t}, C_{p v}\right)^{T}$ is the vector composed by the prices of different elements.

The goal of the second sub-problem is to maximize the average of DG efficiency in the concerned period, as

$$
\begin{aligned}
\max F_{2}(\boldsymbol{\theta}) & =\sum_{k=0}^{N_{\mathcal{T}}} \eta_{D G}(k \Delta t) \\
\text { s.t. } \quad \boldsymbol{\theta} & \in \boldsymbol{\Theta}
\end{aligned}
$$

The objective of the third sub-problem is to minimize the loss of power supply probability (LPSP) $F_{3}$, as

$$
\begin{aligned}
\min F_{3}(\boldsymbol{\theta}) & =\frac{\sum_{t=0}^{N_{\mathcal{T}}} E D(k \Delta t)}{\sum_{t=0}^{N_{\mathcal{T}}} P_{\text {load }}(k \Delta t) \Delta t} \\
\text { s.t. } \quad \boldsymbol{\theta} & \in \boldsymbol{\Theta}
\end{aligned}
$$

where $E D$ is energy deficit which can be expressed, for all $t \in \mathcal{T}$, by

$$
E D(t)=P_{l o a d}(t)-\left(P_{p v}(t)+P_{D G}(t)+P_{b a t}(t)\right)
$$

The defined three sub-problems do not possess necessarily a common solution. Thus, the problem of sizing optimization can be formulated as the following multi-objective optimization problem.

$$
\begin{aligned}
\min & \left\{F_{1}(\boldsymbol{\theta}),-F_{2}(\boldsymbol{\theta}), F_{3}(\boldsymbol{\theta})\right\} \\
\text { s.t. } \quad \boldsymbol{\theta} & \in \boldsymbol{\Theta}
\end{aligned}
$$

For ensuring a minimal efficiency of DG functioning and a limited power loss, we consider the following constraints

$$
\left\{\begin{array}{l}
F_{2}(\boldsymbol{\theta}) \geq F_{2}^{\text {min }} \\
F_{3}(\boldsymbol{\theta}) \leq F_{3}^{\text {max }}
\end{array}\right.
$$

\section{B. Solving strategy}

In order to solve the multi-objective optimization problem described in (11), Non-dominated Sorting Genetic AlgorithmII (NSGA-II) is applied. The whole flowchart of NSGA-II based sizing is given in Fig. 5 and abstracted as Algorithm I. The solving strategy is based on simulation results. The postsimulation constraints (12) are added to the problem after several simulation runs. Note that the details on crossover, mutate and evolution procedures used in the algorithm are not provided in this paper, but can be found in [15]. 


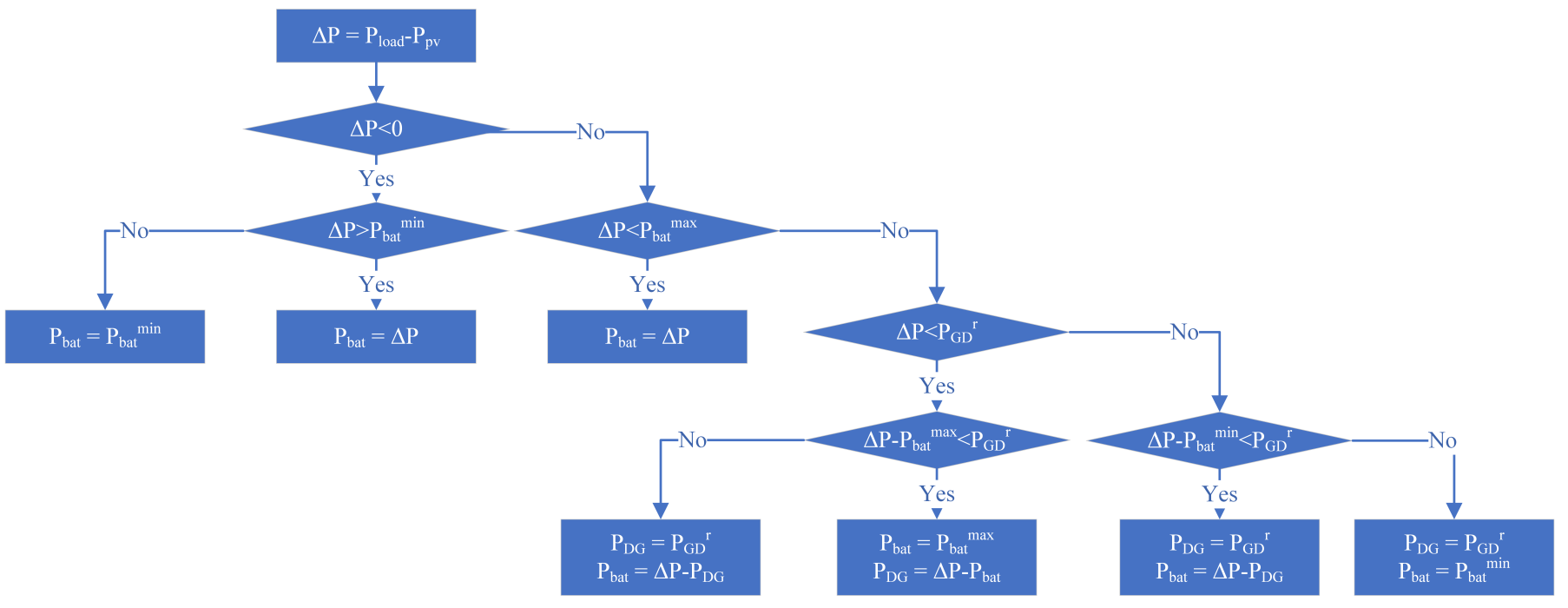

Fig. 4. Flowchart of rule-based energy management

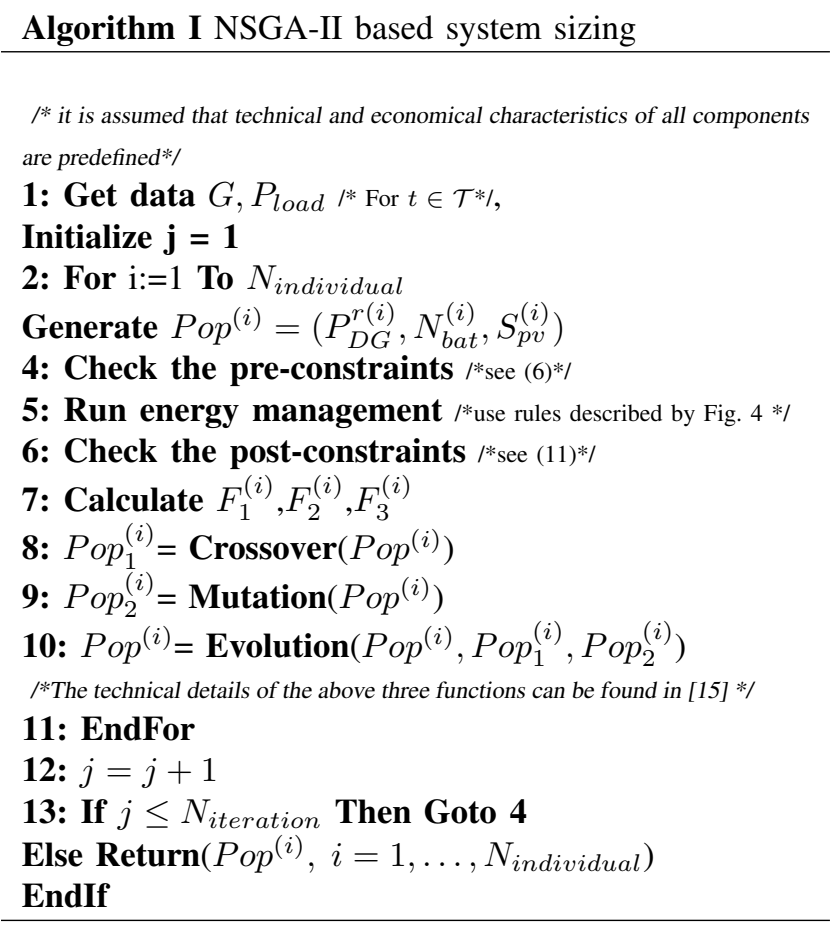

\section{RESUlTS AND DisCUSSION}

\section{A. Studied case}

The proposed sizing strategy is applied to one case where a mobile hybrid energy system is designed for one manufacturer of industrial products. The data of the load power and the local solar radiation in one year are recorded with the sample time $\Delta t=1 h$. The technical parameters of the concerned PV panel and battery are listed in Table I.

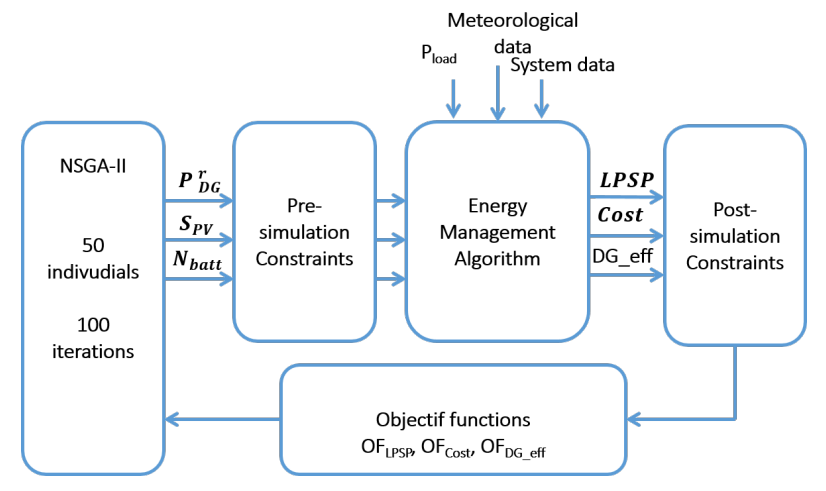

Fig. 5. Optimal sizing process

TABLE I

TECHNICAL PARAMETERS OF THE SYSTEM

\begin{tabular}{ccccccc}
\hline$A_{P V}$ & $\eta_{P V}$ & $S O C^{\max }$ & $S_{O C C^{\min }}$ & $T_{c h}$ & $T_{d c h}$ & $E_{b a t}^{\max }$ \\
\hline $1.64 \mathrm{~m}^{2}$ & 0.17 & 1 & 0.4 & $2 \mathrm{~h}$ & $0.5 \mathrm{~h}$ & $0.5 \mathrm{kWh}$ \\
\hline
\end{tabular}

\section{B. Energy management results}

To verify the effectiveness of energy management strategy, the power separation, SOC, battery power, and DG efficiency of $24 \mathrm{~h}$ with one solution in the optimal sizing set are shown respectively in Fig. 6, Fig. 7, Fig. 8 and Fig. 8. It can be seen that $S O C$ evolves between the limits and the functioning power points of battery are all within the feasible functioning zone. The DG efficiency is maintained at relatively high values (higher than 0.8) when DG is activated.

\section{Sizing results}

Fig. 10 shows the front Pareto optimal solutions. It can be noticed that for lower LPSP values, the total cost investment can vary in a wide range. In our study, we choose a solution 


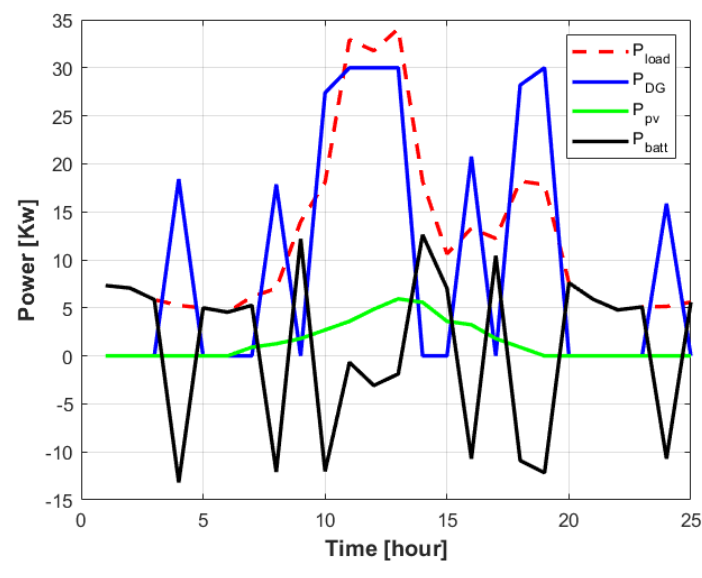

Fig. 6. Power flow during 24 hour

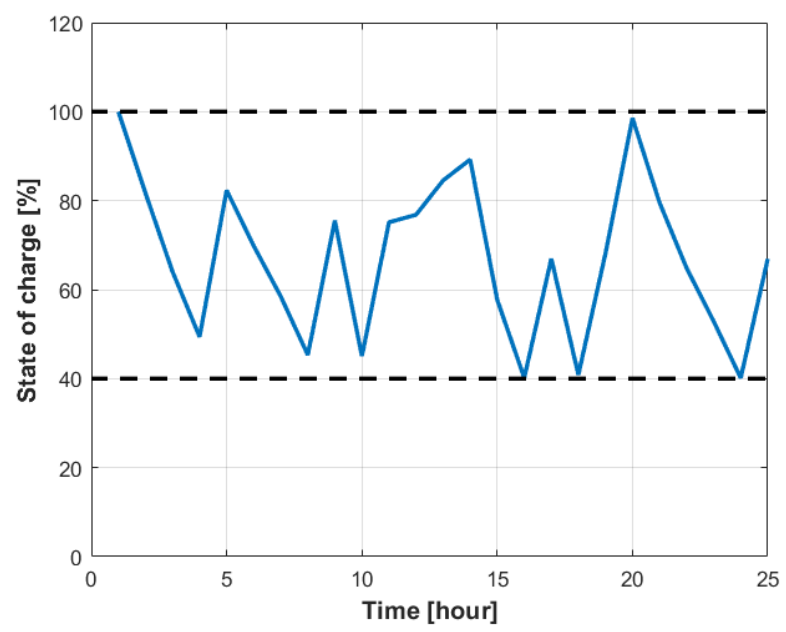

Fig. 7. State of charge

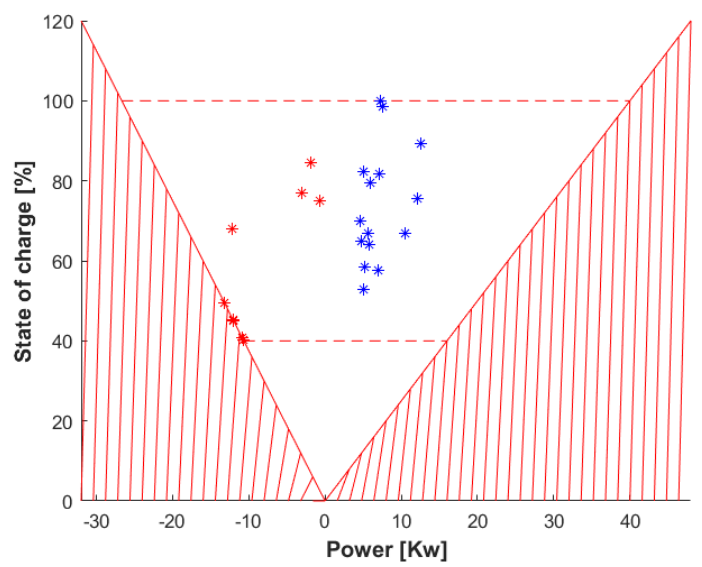

Fig. 8. Battery function points

with an LPSP value of $0.9 \%$, and a total cost of $24 k$. The three criteria corresponding the solution is shown in the figure.

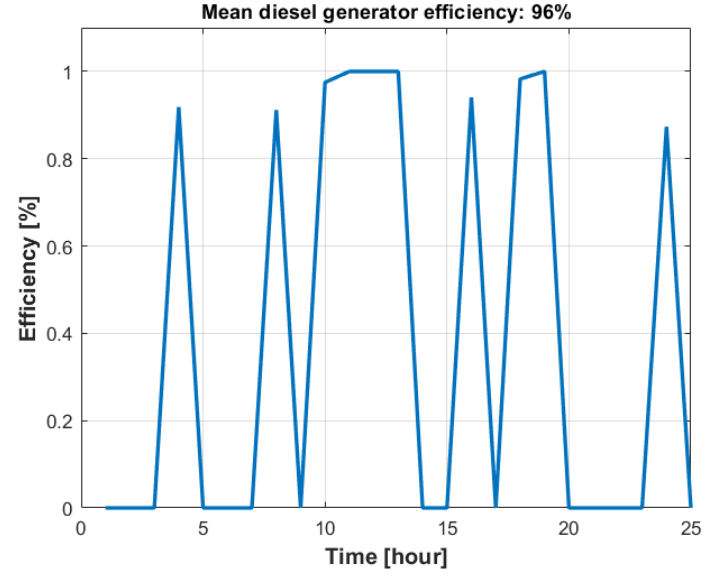

Fig. 9. DG efficiency

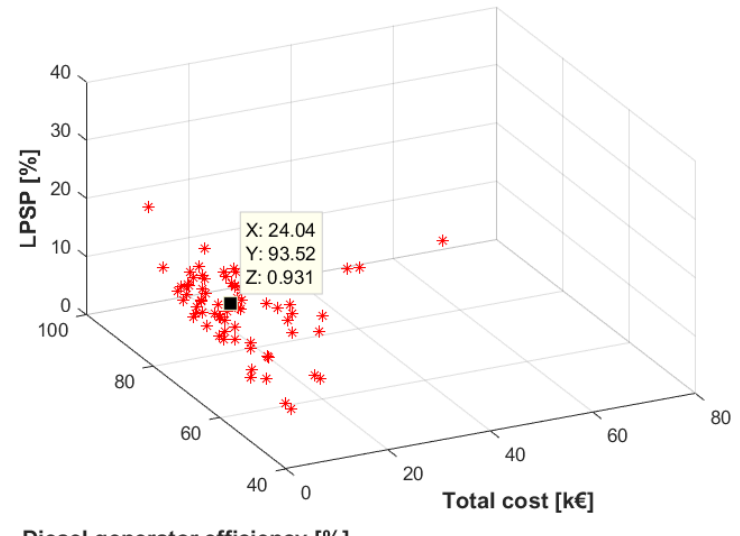

Diesel generator efficiency [\%]

Fig. 10. Optimization results

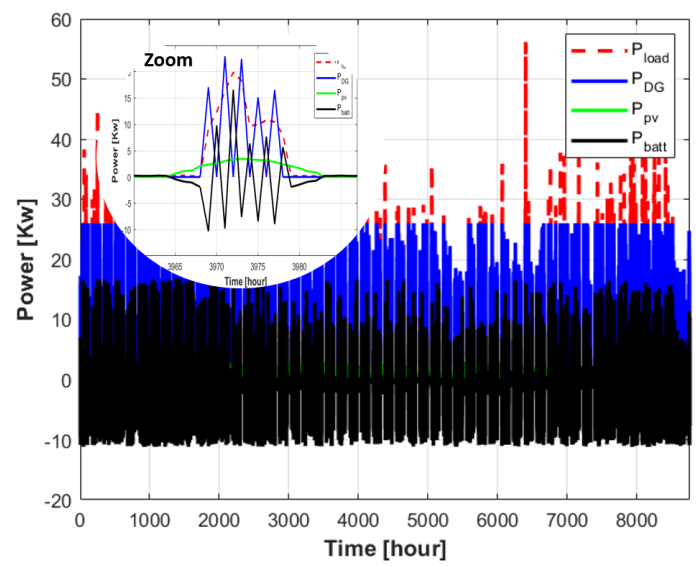

Fig. 11. Hybrid system power

Only the peak load consumption is not guaranteed, as shown in Fig. 11. The adopted energy management allowed a high efficiency of the DG with a mean value of $93 \%$ during the period $\mathcal{T}$. 


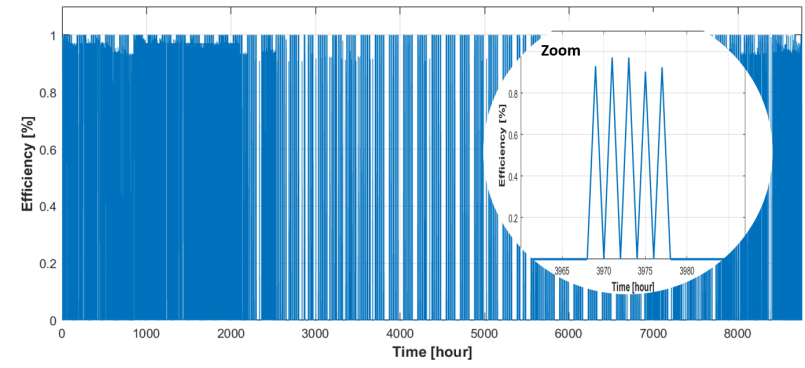

Fig. 12. DG efficiency

The Fig. 13 and 14 show that battery limits are respected according to the SOC value and charging and discharging power limits. However, in Fig. 14, we note that the discharging operating points are far away from the discharging limit. Therefore, it could be more financially interesting to use another battery technology with different discharging constraints.

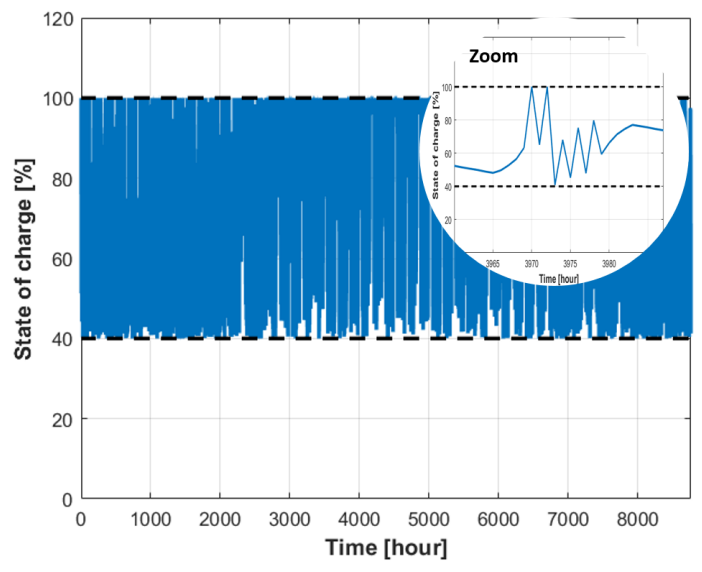

Fig. 13. Battery state of charge

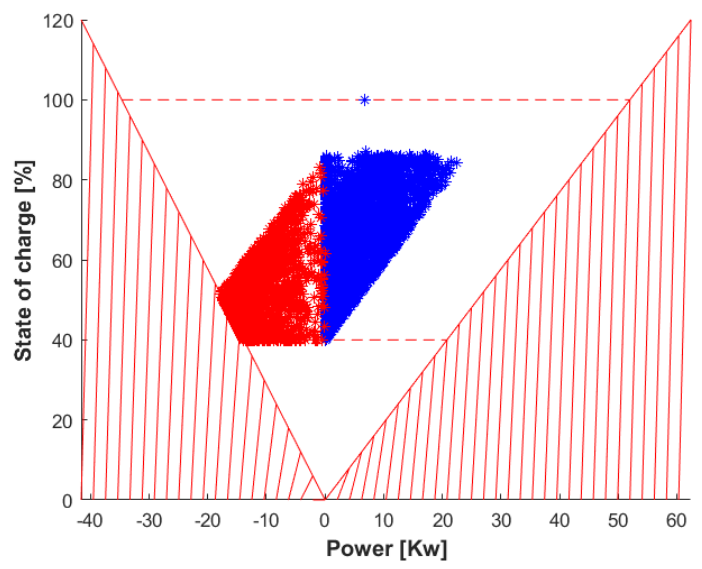

Fig. 14. Battery function points

\section{CONCLUSION}

In this study, a sizing optimization problem of a mobile renewable hybrid off-grid power system is studied. A multiobjective NSGA-II is proposed to solve the problem according to the system constraints. The optimization process takes into account the energy management to ensure a high operating efficiency of the DG and to maximize the photovoltaic contribution. This study can be extended to any other type of renewable energies (wind turbine, hydro power, etc.), depending on the local renewable resources, and it can be adapted to any particular consumer needs.

\section{REFERENCES}

[1] D. K. Neitzel, "Electrical safety when using temporary power," 2016 Petroleum and Chemical Industry Technical Conference, PCIC 2016, pp. 1-8, 2016.

[2] M. Eroglu, E. Dursun, S. Sevencan, J. Song, S. Yazici, and O. Kilic, "A mobile renewable house using PV/wind/fuel cell hybrid power system," International Journal of Hydrogen Energy, vol. 36, no. 13, pp. 7985-7992, 2011. [Online]. Available: http://dx.doi.org/10.1016/j.ijhydene.2011.01.046

[3] Z. Xiaofei, W. Zhen, and S. Zhou, "How to ensure the modular ups with high reliability," in 2015 IEEE International Telecommunications Energy Conference (INTELEC), Oct 2015, pp. 1-4.

[4] C. V. Nayar, M. Ashari, and W. W. Keerthipala, "A grid-interactive photovoltaic uninterruptible power supply system using battery storage and a back up diesel generator," IEEE Transactions on Energy Conversion, vol. 15 , no. 3, pp. 348-353, 2000.

[5] T. Ma, H. Yang, and L. Lu, "Study on stand-alone power supply options for an isolated community," International Journal of Electrical Power and Energy Systems, vol. 65, pp. 1-11, 2015.

[6] M. Braun, J. Brombach, C. Hachmann, D. Lafferte, A. Klingmann, W. Heckmann, F. Welck, D. Lohmeier, and H. Becker, "The future of power system restoration: Using distributed energy resources as a force to get back online," IEEE Power and Energy Magazine, vol. 16, no. 6, pp. 30-41, Nov 2018.

[7] R. Outbib, X. Dovifaaz, A. Rachid, and M. Ouladsine, "A theoretical control strategy for a diesel engine," Journal of dynamic systems, measurement, and control, vol. 128, no. 2, pp. 453-457, 2006.

[8] G. Van Straten, "Mobile electricity generator using solar, wind, and fuelgenerated power," Oct. 23 2012, uS Patent 8,295,033.

[9] D. McGuire, "Portable, self-sustaining power station," Aug. 21 2008, uS Patent App. 11/965,422.

[10] S. Upadhyay and M. P. Sharma, "A review on configurations, control and sizing methodologies of hybrid energy systems," Renewable and Sustainable Energy Reviews, vol. 38, pp. 47-63, 2014. [Online]. Available: http://dx.doi.org/10.1016/j.rser.2014.05.057

[11] M. Fadaee and M. A. Radzi, "Multi-objective optimization of a stand-alone hybrid renewable energy system by using evolutionary algorithms: A review," Renewable and Sustainable Energy Reviews, vol. 16, no. 5, pp. 3364-3369, 2012. [Online]. Available: http://dx.doi.org/10.1016/j.rser.2012.02.071

[12] A. S. Al Busaidi, H. A. Kazem, A. H. Al-Badi, and M. Farooq Khan, "A review of optimum sizing of hybrid PV-Wind renewable energy systems in oman," Renewable and Sustainable Energy Reviews, vol. 53, pp. 185-193, 2016. [Online]. Available: http://dx.doi.org/10.1016/j.rser.2015.08.039

[13] A. Kaabeche, M. Belhamel, and R. Ibtiouen, "Techno-economic valuation and optimization of integrated photovoltaic/wind energy conversion system," Solar energy, vol. 85, no. 10, pp. 2407-2420, 2011.

[14] B. K. Das, Y. M. Al-Abdeli, and M. Woolridge, "Effects of battery technology and load scalability on stand-alone PV/ICE hybrid microgrid system performance," Energy, vol. 168, pp. 57-69, 2019. [Online]. Available: https://doi.org/10.1016/j.energy.2018.11.033

[15] K. Deb, A. Pratap, S. Agarwal, and T. Meyarivan, "A fast and elitist multiobjective genetic algorithm: Nsga-ii," IEEE Transactions on Evolutionary Computation, vol. 6, no. 2, pp. 182-197, Apr 2002. 